\title{
Building a Stronger Supply Chain: Lessons From the Crisis
}

\section{David Johnston (Schulich School of Business, York University)}

KEYWORDS: Management, Supply chain, Purchasing.

Part one of a two-part series. Read part 2 here (https://eiexchange.com/content/get-ready-for-the-nextsupply-chain-disruption)

Two questions currently dominate the emerging post Covid-19 economy. Most immediately: When will I get what I ordered? More long term: How do I assure reliable delivery of the goods and services I depend upon?

To answer those questions, organizations are discovering or revisiting the importance of having a resilient and sustainable supply chain strategy. In the future we're expecting more frequent, sudden, systemic supply disruptions, whether they be from pandemics, climate change and/or trade disputes. Organizations must have stress-tested solutions and strategies to weather these problems.

This article will not dwell on the specific disruptions that are "bottlenecking" most economies right now, such as a shortage of shipping containers, capacity at ports, factory capacity to make common components such as microchips, or shortages of skilled supply chain workers and managers. The impact and potential duration of these shortages vary considerably across sectors. Instead, we will focus on what small and medium firms can do to be more resilient in a future where demand and supply disruptions are more certain. Let's start with a 360-degree view of the organization's supply chain activities and what a capable supply chain function looks like.

\section{Supply Chain 101}

Supply chain management is all about providing product and services -- with the right quality at the right time, price and place -- to satisfy an end customer, $100 \%$ of the time. Reaching this ideal requires professionals who understand how doing "right" translates into specific performance standards, and which systems help make the right decisions at the right time.

I've talked to major retailers and manufacturers about how they coped with the bust, then boom, in the products and services they bought and sold during the pandemic. From these conversations l've learned that the best companies accelerated their efforts to improve their capabilities to achieve the above ideal. Organizations that didn't do this before the pandemic were hampered by a profound strategic weakness as they scrambled to stay in business during the wild supply and demand fluctuations of the pandemic.

Let's do a deeper dive into the three critical components of a supply chain management capability and what companies should do to buffer and bridge an organization over supply disruptions.

\section{Sourcing}

Whether you are selling as a retailer, manufacturer or service provider, your organization is also a buyer. Most organizations of sufficient size have a purchasing function that manages the supply base. In less capable organizations these people have a limited role: they may process purchase orders when told what to buy by others, pay bills and make sure goods are received. They sometimes police spending and scrutinize employee requests for spending. But if a key supplier stops shipping, slips in quality, or consistently delivers late, these purchasing people can't even begin to understand the root causes.

Capable organizations are constantly searching for new suppliers of commodities that have been identified as strategic to the organization. They scrutinize potential suppliers' ability to deliver quality products at a reasonable price point. They engage frequently with their most important suppliers to explore how the process can be made more efficient and responsive. And when disaster strikes, the purchasing organization knows exactly who at the supplier organization can best protect their interests.

\section{Logistics}

Most organizations have either a function that handles the movement of goods or a service provider that does 
this for them: a major courier company, third-party logistics provider and/or transportation carrier. Logistics may also involve dispatching service people to customers. Imagine links drawn on a whiteboard between suppliers, you and your customers for any product, then multiplied across product lines and sometimes geographic regions (including national borders). You'll soon see a complex, tangled logistical network with many players to coordinate.

Capably managing logistics means understanding this end-to-end flow of product and services and where "pinch points" can make the supply vulnerable to disruption. An advanced understanding of alternative providers, routing and waypoints to stockpile product can be a lifesaver in times of supply disruption -whether it's a port disrupted by labor shortages or unrest, a critical piece of infrastructure failing due to flooding, or a hurricane that grounds air freight in a region. Less capable organizations watch helplessly as their products languish in warehouses far from customers, to expire ( e.g., food) or lose value over time (e.g., food, fashion and consumer electronics).

\section{Demand Planning}

The most capable organizations have people who can collect and analyze data to forecast customer orders, calculate the volume of product to make or services that can deliver given the organization's capacity, then determine the timing and number of component products to be ordered. Their decisions affect financial stability: how much inventory to carry, and how many people to hire and machines to buy to ensure capacity. "How much, and when" are critical factors for Sourcing and Logistics.

Capable demand planners always focus on minimizing the cash-to-cash cycle. That is, they collect receivables from customers before or soon after they have to pay suppliers and their own employees. They time product deliveries to minimize carrying costs and the risk of an obsolete product, or they produce only when the customer has committed to payment. Inventory and extra capacity when necessary are treated as an investment, or "insurance," to assure that customers get their orders fulfilled. Less capable demand planners are always either stocking out or running out of high-margin products, or getting whipsawed between idle capacity and processes stressed running overtime.

\section{Three Lessons from the Current}

\section{Supply Disruption}

In all components of the supply chain capability -sourcing, logistics and demand planning - these three factors have helped organizations weather the current disruption.

\section{They Manage Information Flow as Well As Product}

Flows. Supply chain management is a knowledgeintensive business that begins with people talking about what is important. Some disruptions, such as a hurricane, may not give organizations much time to react. But others, such as shortages due to too few suppliers and factory closures (e.g., PPE and lumber earlier on in the pandemic), give early warning signs that should trigger alternative buying and stockpiling. In these cases "hard" quantitative information matters less than "business intelligence." Strong communication channels with suppliers and customers can provide a valuable early warning system. For sudden and unpredictable disruptions, such as factories closing down due to a loss of electrical supply in China, having trusted lines of communication in place with informed stakeholders makes it easier to implement Plan B. Information systems that flag early changes in customers' ordering patterns and detect supplier delivery problems can also be part of an early warning system and support a rapid response. These systems can be automated through the tracking functions of order and freight management systems. But they require people with on-the-ground knowledge of the overall industry supply environment outside the organization to analyze the warning signs and make the right decisions.

They Diversify Supply Risk. Over the past few decades the quest for leaner supply chains has led to consolidated supply bases, outsourcing and offshoring. This lean approach can lower unit costs but it can also make supply chains more vulnerable. During a disruption the product supply dwindles and whatever remains costs more, reflecting scarcity pricing. This disables the cash-to-cash cycle and can put the organization out of business. During the pandemic, purchasers scrambled to find alternative suppliers (such as for PPE); logisticians had to find new truck carriers and warehousing space providers; and demand planners longed for more inventory to stock store shelves. Just-in-time delivery of product and services may be an ideal in stable times, but the logic of just-incase tends to dominate when supply disruptions threaten. It may be prudent to invest in some 
redundancy, whether that's having alternative suppliers and logistical providers or holding more inventory as "safety" stock.

They Focus on Customer Retention. During Covid-19 very few businesses were immune to rationing, either in the supplies they could purchase or the products and services they could sell. Organizations that weathered the supply disruption knew how they made money and what they had to do to retain customers: what was essential versus what was "nice to have." This allowed them to allocate suppliers and employee time and money to maintaining the core of the organization's mission. For example, they concentrated on producing and stocking customer staples that encouraged repeat purchases, rather than infrequent ones making discretionary purchases. Supply shortages are forced "moments of truth" that should lead to greater focus on key customers and products.

\section{Learn More}

Part two of our feature on supply chain resilience focuses on how to protect your company from the next crisis. Read here.(https://eiexchange.com/content/get-ready-for-thenext-supply-chain-disruption)

The New Normal: Overcoming Post-Pandemic Challenges to Survival and Growth (https://eiexchange.com/content/the-new-normalovercoming-post-pandemic-challenges-to-survival) 